\title{
FLORAÇÃO DA VARIEDADE TOBIAS (Citrus sinensis Osbeck.) SOBRE TRÊS PORTA- ENXERTOS NO VALE DO TAQUARI-RS ${ }^{1}$
}

\author{
SOLANGE MACHADO TONIETTO ${ }^{2} \&$ ADILSON TONIETTO ${ }^{2}$
}

\begin{abstract}
RESUMO - O objetivo do trabalho foi determinar a plena floração (70\% de flores abertas) de uma variedade cítrica no Vale do Taquari - RS, no ano de 2003. O trabalho foi realizado no Centro de Pesquisa de Fruticultura de Taquari, em um pomar de laranjeira Tobias, com 16 anos de idade, e enxertado sobre os seguintes porta-enxertos: C13, Poncirus trifoliata e Laranjeira Caipira, denominadas de Tobias 1, Tobias 2 e Tobias 3, respectivamente. A data utilizada como início da floração foi 1\%/09/2003. A plena floração foi estimada em 16-07 para a variedade Tobias enxertada sobre C13 e Poncirus trifoliata e 19-07 sobre Laranjeira Caipira; a combinação Tobias 2 apresentou a data de plena floração antes da Tobias 3; o quadrante Sul reduz a média da plena floração da Laranjeira Tobias sobre a Laranjeira Caipira (Tobias 3).
\end{abstract}

Termos para indexação: Citros, florescimento, porta-enxerto, quadrantes

\section{BLOOM OF TOBIAS VARIETY (Citrus sinensis Osbeck.) ON THREE ROOTSTOCKS IN TAQUARI VALLEY, RS}

ABSTRACT - The objective of this work was to determine the date of the full bloom (70\% of open flowers) in a citric variety in Taquari Valley - RS, in 2003. The work was carried out in the Research Center of Fruticulture of Taquari, in an orchard with 16 years old. The variety of citrus studied was the Tobias on three rootstocks: C13, Poncirus trifoliata and orange tree Caipira, called Tobias 1, Tobias 2 e Tobias 3, respectively. The date considered the beginning of flowering was 09/01/2003. The full bloom was estimated in 07/16 to Tobias variety on C13 and Poncirus trifoliata rootstock and 07/ 19 on Caipira orange tree; the combination Tobias 2 showed the date of full bloom before Tobias 3; the South quadrant reduces the media of the full bloom of the Tobias orange tree on Caipira orange tree (Tobias 3).

Index terms: Citrus, flowering, rootstock, quadrants

\section{INTRODUÇÃO}

As plantas cítricas têm ampla distribuição geográfica, adaptando-se a diferentes condições climáticas, o que determina comportamentos diferenciados das plantas e variações entre locais e anos, nas características fenológicas da floração.

Determinar o ponto de colheita é fundamental para a conservação pós-colheita, sendo a imaturidade e o superamadurecimento responsáveis por 4 a $12 \%$ de perdas.

De acordo com Velarde (1991), a determinação da data da plena floração é considerada como um dado-base para os cultivos, pois este dado é específico de uma variedade e é influenciado pelo microclima, conferindo a sua determinação caráter puramente local.

Terra et al. (1998), estudando a fenologia de videira, afirmaram que na introdução de novas variedades, a fenologia desempenha importante função, pois permite a caracterização da duração das fases do desenvolvimento da plantas em relação ao clima, especialmente às variações estacionais, além de ser utilizada para interpretar como as diferentes regiões climáticas interagem com a cultura.

A fenologia varia em função do genótipo e das condições climáticas de cada região produtora, ou em uma mesma região, devido às variações estacionais do clima ao longo do ano (Leão e Silva, 2003). Erickson (1968) cita que, além das condições climáticas, doenças, condições de irrigação ou falta de água também afetam a floração dos citros.

Dependendo da latitude em que uma determinada região se encontra, as plantas cítricas estarão expostas a diferentes regimes de energia, temperatura e distribuição da intensidade luminosa. As diferenças entre estes fatores têm efeitos importantes na taxa fotossintética diária e, consequientemente, no desenvolvimento da planta.

De acordo com Rocha et al. (1990), conforme a posição do órgão na planta, teremos diferentes respostas quanto ao seu desenvolvimento, haja vista que os índices de radiação e luminosidade diferem em cada quadrante. Portanto, dependendo da orientação do pomar, as plantas serão expostas a diferentes regimes de insolação e comportamentos diferenciados em suas fases fenológicas.

A adequada seleção de um porta-enxerto é fundamental no êxito de uma plantação citrícola, pois ela exerce influência na adaptação a diferentes condições edafoclimáticas, tolerância a doenças, níveis de produção e qualidade da fruta ( Dornelles, 1978; Bravo e Gallardo, 1994). Machado e Mendez (1999) constataram que a variedade Valência sobre o porta-enxerto Poncirus trifoliata foi de maturação mais precoce que sobre o porta-enxerto Laranjeira Caipira.

A caracterização das exigências térmicas mediante o conceito de graus-dia - que é a quantidade de calor exigida por uma planta para que os seus frutos maturem - tem sido utilizada por diversos autores, em diversas culturas, sendo assim um método eficiente para prever antecipadamente a data da colheita.

O objetivo do trabalho foi determinar a plena floração de uma variedade cítrica no Vale do Taquari - RS, no ano de 2003, obtendo-se, assim, a data onde se inicia a soma térmica para, posteriormente, determinar a época de colheita da variedade Tobias, através dos parâmetros de qualidade das frutas.

\section{MATERIAL E MÉTODOS}

O trabalho foi realizado no Centro de Pesquisa de Fruticultura de Taquari, que está localizado no município de Taquari, Vale do Taquari - RS, latitude 29048'15", longitude 51049'30" e altitude 76m.

A variedade de citros estudada foi a Tobias sobre três portaenxertos: C13, Poncirus trifoliata e Laranjeira Caipira, as quais foram denominadas de Tobias 1, Tobias 2 e Tobias 3, respectivamente. Utilizouse um pomar com 16 anos de idade, onde foram selecionadas seis plantas de cada porta-enxerto, totalizando 18 plantas. Os cachos florais foram identificados na parte mediana da planta com etiquetas em cada quadrante (Norte, Sul, Leste e Oeste), ao acaso. Realizaram-se as contagens de flores a partir de $1^{\circ}$ de setembro de 2003, quando se iniciou a abertura das mesmas, em intervalos de dois a três dias. Considerou-se como plena floração o momento em que se alcançou $70 \%$ da abertura das flores.

Para determinar o período do início da floração até a plena floração, foi utilizada a data de $1^{\circ}$ de setembro de 2003 .

\section{RESULTADOS E DISCUSSÃO}

Os resultados demonstram, através da análise de variância,

\footnotetext{
${ }^{1}$ (Trabalho 061/2004). Recebido: 16/04/2004. Aceito para publicação: 21/02/2005.

${ }^{2}$ Engenheiro(a) Agrônomo (a), Dr(a)., Pesquisador(a) da Fepagro Sede, Rua Gonçalves Dias, 570, CEP:90130-060, Menino Deus, Porto Alegre, RS, Fone:(051)32888087, e-mail: tonietto@universiabrasil.net; adilson-tonietto@ fepagro.rs.gov.br.
} 
que houve diferença significativa para as interações: porta-enxertos datas e porta-enxertos - quadrantes. Na Figura 1, ao comparar a variedade Tobias 1, Tobias 2 e Tobias 3, observou-se que as duas primeiras tiveram comportamento semelhante, atingindo a plena floração antes de 18 de setembro (última leitura), enquanto a Tobias 3 não alcançou a plena floração, atingindo apenas $62,16 \%$ das flores abertas nessa mesma data (Figura 2). Ainda na Figura 2, observa-se que houve diferença significativa na floração, entre Tobias 2 e Tobias 3, na data de 18 de setembro, verificando-se que Tobias 3 não atingiu a plena floração nessa data $(62,16 \%)$. Entretanto, Tobias 1 não diferiu estatisticamente dos demais porta-enxertos.

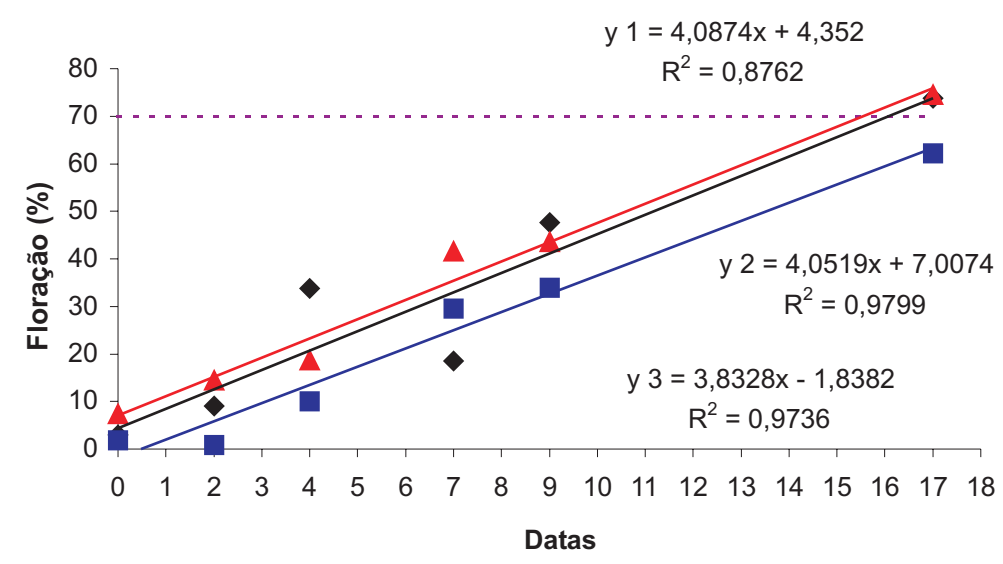

$\begin{array}{ccc}\text { - Tobias } 1 & \text { Tobias } 3 \\ \text { \ Tobias } 2 & \text {. . - . - . Plena Floração }\end{array}$

FIGURA 1 - Floração da variedade Tobias sobre C13 (Tobias 1), Poncirus trifoliata (Tobias 2) e Laranjeira Caipira (Tobias 3) em Taquari - RS, 2003.

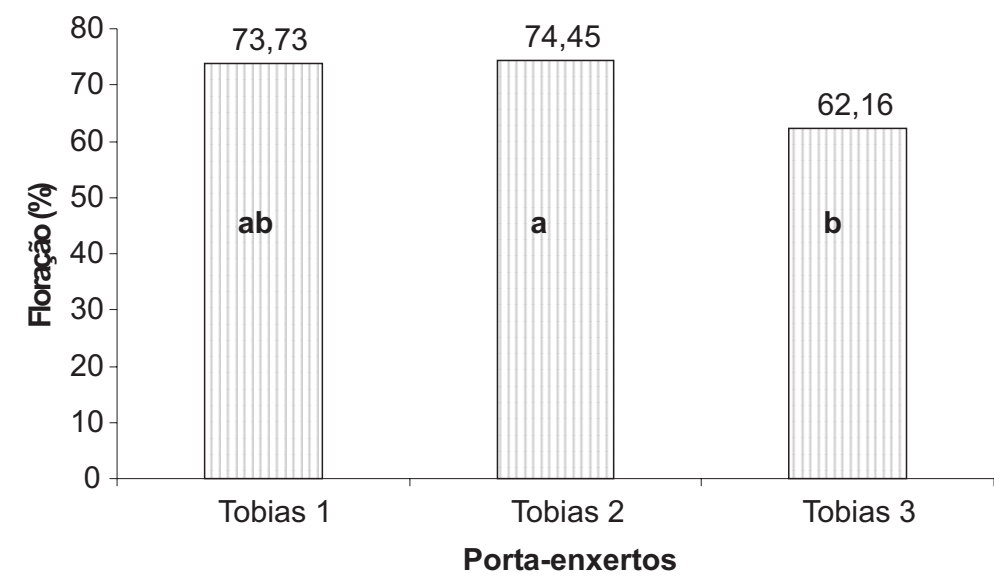

FIGURA 2 - Floração da variedade Tobias sobre C13 (Tobias 1), Poncirus trifoliata (Tobias 2) e Laranjeira Caipira (Tobias 3), em 18 de setembro de 2003. Taquari-RS.

Médias seguidas pela mesma letra não diferem estatisticamente, pelo Teste de Tukey, a 5\% de probabilidade.

Utilizando-se da curva de tendência do comportamento da floração para cada um dos porta-enxertos, verifica-se que as combinações copa e porta-enxertos atingiram a plena floração em 16; 16 e 19 de setembro de 2003 para Tobias 1, Tobias 2 e Tobias 3, respectivamente.

Machado et al. (1997), ao estudarem a floração da variedade Valência sobre os porta-enxertos Poncirus trifoliata e Laranjeira Caipira, na região de Pelotas - RS, verificaram que a variedade Valência sobre o porta-enxerto Laranjeira Caipira apresentou floração antecipada em relação à mesma variedade sobre o porta-enxerto Poncirus trifoliata.

Já, em Taquari, a variedade Tobias sobre o porta-enxerto Poncirus trifoliata apresentou floração antecipada em relação à mesma variedade sobre porta-enxerto Laranjeira Caipira.

Rossi et al. (2000), estudando a intensidade do florescimento em diversas variedades de laranjeiras na região de Pelotas, observaram que, em relação ao número de dias para atingir $70 \%$ de flores abertas, a Laranjeira Caipira foi significativamente mais precoce que as demais variedades analisadas.

Supõe-se não apenas o efeito do porta-enxerto sobre a copa, mas também o efeito de um complexo de fatores, que incluem a variedade copa e os fatores climáticos de cada região, que atuam sobre o comportamento fenológico das copas.

Com relação aos quatro quadrantes estudados (Figura 3), verificou-se que os quadrantes Norte, Leste e Oeste não diferiram estatisticamente quanto à floração em 18 de setembro. Já o quadrante Sul diferiu dos demais nessa data, com cerca de $54 \%$ das flores abertas. $\mathrm{Na}$ Figura 4, observou-se que, para Tobias 1 e Tobias 2 na data de 18 de setembro, não houve diferença significativa na floração entre quadrantes. Porém, para Tobias 3, houve diferença significativa no quadrante Sul em relação aos demais quadrantes.

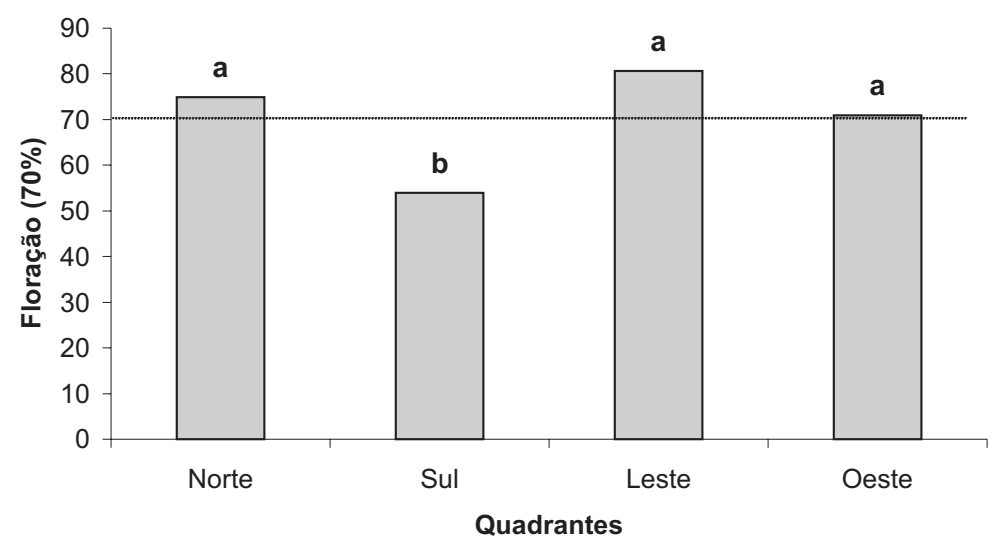

FIGURA 3 - Floração da variedade Tobias por quadrante. Taquari - RS, 2003. Médias seguidas pela mesma letra não diferem estatisticamente, pelo Teste de Tukey, a 5\% de probabilidade.

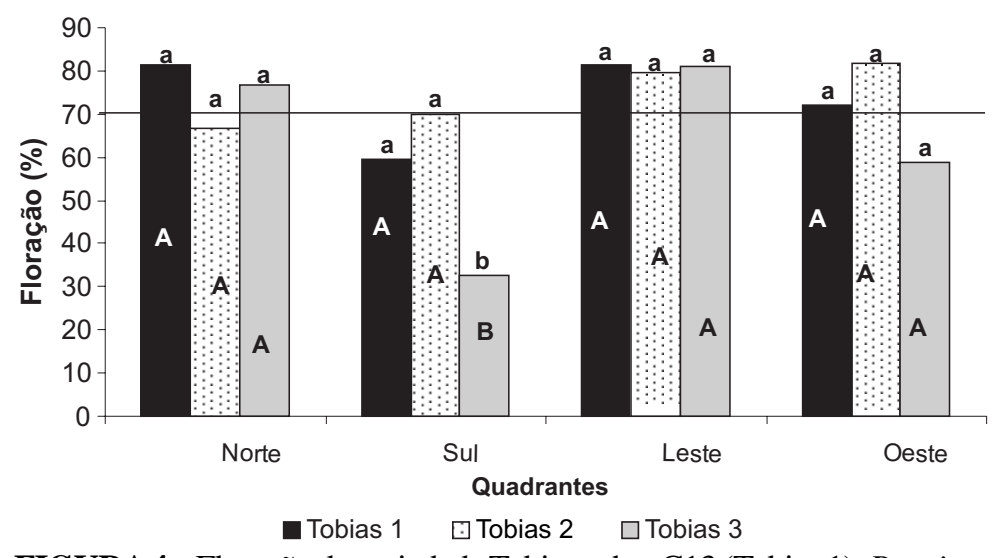

FIGURA 4 - Floração da variedade Tobias sobre C13 (Tobias 1), Poncirus trifoliata (Tobias 2) e Laranjeira Caipira (Tobias 3) por quadrante, em 18 de setembro de 2003. Taquari - RS. Médias seguidas pela mesma letra, minúscula entre porta-enxertos e maiúscula entre quadrantes, não diferem estatisticamente, pelo Teste de Tukey, a $5 \%$ de probabilidade.

O quadrante Sul determinou a menor média de floração para Tobias 3, enquanto Tobias 1 e 2 apresentaram médias iguais (Figura 4). Koller (1994) cita que, nas partes sombreadas da copa, não há florescimento, e as folhas tornam-se mais escassas, culminando com a morte dos ramos excessivamente sombreados. Desta forma, acredita-se que a baixa percentagem de floração no quadrante Sul da Tobias 3 ocorreu devido à menor incidência da radiação solar neste ponto cardeal.

Como se pode verificar na Figura 2, na Tobias 1 e Tobias 2, todos os quadrantes tiveram comportamentos iguais. Desta forma 
acredita-se que haja diferença entre os porta-enxertos e na reação à menor incidência da radiação solar. Disto supõe-se que a Tobias 3 apresenta menor floração, devido à menor adaptação a locais sombreados.

Estas diferenças constatadas entre as combinações copa e porta-enxerto servirão para analisar se haverá influência na época de maturação das frutas e como a soma térmica age sobre estas combinações. Isso vem contribuir para as observações de utilização de porta-enxertos nas diversas regiões, na busca das melhores combinações, e mesmo porta-enxertos que possibilitem a melhor adaptação das plantas às diferentes regiões.

Pode-se observar a similaridade entre os porta-enxertos Poncirus trifoliata e C13, que poderá ser devida à origem do C13, pois é um Citrange - híbrido originário dos cruzamentos entre Poncirus trifoliata e Citrus sinensis.

\section{CONCLUSÕES}

1. A plena floração foi estimada no dia 16-09 para a variedade Tobias sobre o porta-enxerto C13 ou Poncirus trifoliata e 19-09 sobre a Laranjeira Caipira.

2. A utilização do porta-enxerto Poncirus trifoliata possibilitou à Laranjeira Tobias atingir a plena floração antes do que quando sobre o porta-enxerto Laranjeira Caipira.

3. O quadrante Sul reduz a média da plena floração da Laranjeira Tobias sobre a Laranjeira Caipira, não havendo influência dos outros quadrantes sobre esta e as outras combinações com porta-enxertos.

\section{REFERÊNCIASBIBLIOGRÁFICAS}

BRAVO, I. M. de; GALLARDO, E. Comportamiento del naranjo "Valência" sobre trece patrones en Lara, Venezuela. II. Produccion y calidade de fruta. Agronomia Tropical, Maracary, v.44, n.4, p.629643, 1994.
DORNELLES, C. M. M. O problema dos porta-enxertos para citros no Rio Grande do Sul. Boletim Técnico, Porto Alegre, v.2, p.121-27, 1978.

ERICKSON, L.C. The general Physiology of citrus. In: REWTER, W. et al. (Ed.). The citrus industry. Riversaid: University of California, 1968. v.2, cap.2, p.86-126.

KOLLER, O. C. Citricultura: laranja, limão e tangerina. Porto Alegre: Editora Rígel, 1994. 446p.

LEÃO, P.C. de; SILVA, E.E.G. da. Caracterização fenológica e requerimentos térmicos de variedades de uvas sem sementes no Vale do São Francisco. Revista Brasileira de Fruticultura, Jaboticabal, v. 25, n. 3, p. 379-382, 2003.

MACHADO, S.O.; MENDEZ, M.E.G. Determinação da época de colheita da laranja variedade Valência (Citrus sinensis L. Osbeck) na região de Pelotas - RS. Revista Científica Rural, Bagé, v.4, n.2, p.91-95, 1999.

MACHADO, S.O.; TONIETTO, A.; MENDEZ, M.E.G. Florescimento da variedade Valência (Citrus sinensis Oesbeck.) sob os porta-enxertos Laranjeira Caipira e Poncirus trifoliata em Pelotas- RS. In: CONGRESSODAPÓS-GRADUAÇÃOEM CIÊNCIAS AGRÁRIAS - UFPel, 1., 1997, Pelotas. Anais... Pelotas: UFPel, 1997. p.71.

ROCHA, A.C.; TAVARES, E.D.; SANDRINI, M., PAIVA, R., CARVALHO, S. A. Época e intensidade de florescimento e pegamento de frutos segundo a distribuição pelos quadrantes em Laranjeiras. Pesquisa Agropecuária Brasileira, Brasília, vol. 25, n.6, p. 85-88, 1990.

ROSSI, A.; RUFATO, L; MENDEZ, M.E.G. Época e intensidade de florescimento de citros de acordo com a distribuição pelos quadrantes. Revista Científica Rural, Bagé, v. 5, n. 1, p. 101-104, 2000.

TERRA, M. M. et al. Tecnologia para produção de uva Itália na região noroeste do estado de São Paulo. 2. ed. Campinas: CATI, 1998. 58p. (Documento Técnico, 97).

VELARDE, F.G.A. Tratado de arboricultura frutal: morfologia y fisiologia del arbolfrutal. Madrid: Ediciones Mundi - Prensa, 1991. 104p. 